Review

\title{
Phosphorescent Organic Light-Emitting Devices: Working Principle and Iridium Based Emitter Materials
}

\author{
Stefan Kappaun $^{1{ }^{1} *}$, Christian Slugove ${ }^{2}$ and Emil J. W. List ${ }^{1,3, *}$ \\ 1 NanoTecCenter Weiz Forschungsgesellschaft mbH, Franz-Pichler-Straße 32, 8160 Weiz, Austria \\ 2 Institute for Chemistry and Technology of Materials, Graz University of Technology, \\ Stremayrgasse 16, 8010 Graz, Austria \\ 3 Institute of Solid State Physics, Graz University of Technology, Petersgasse 16, 8010 Graz, Austria \\ * Authors to whom correspondence should be addressed; E-Mails: stefan.kappaun@ntc-weiz.at; \\ e.list@tugraz.at
}

Received: 11 July 2008; in revised form: 1 August 2008 / Accepted: 1 August 2008 / Published: 26 August 2008

\begin{abstract}
Even though organic light-emitting device (OLED) technology has evolved to a point where it is now an important competitor to liquid crystal displays (LCDs), further scientific efforts devoted to the design, engineering and fabrication of OLEDs are required for complete commercialization of this technology. Along these lines, the present work reviews the essentials of OLED technology putting special focus on the general working principle of single and multilayer OLEDs, fluorescent and phosphorescent emitter materials as well as transfer processes in host materials doped with phosphorescent dyes. Moreover, as a prototypical example of phosphorescent emitter materials, a brief discussion of homo- and heteroleptic iridium(III) complexes is enclosed concentrating on their synthesis, photophysical properties and approaches for realizing iridium based phosphorescent polymers.
\end{abstract}

Keywords: Organic light-emitting devices (OLEDs), electroluminescence, fluorescence, phosphorescence, phosphorescent polymers. 


\section{Introduction}

Since the first observation of organic electroluminescence (i.e. the generation of light by electrical excitation of an organic material) in the 1960s by applying hundreds of volts to an anthracene single crystal [1], in the recent decades the field of organic electronics has progressed enormously [2]. Boosted by the pioneering work of Tang and VanSlyke and the resulting worldwide activity in numerous research groups [3], the advances in the fields of device science, device fabrication as well as chemistry, physics and materials science have evolved organic light-emitting device (OLED) technology to a point where it is now an important competitor to liquid crystals and liquid crystal displays (LCDs) [4-8]. Consequently, the interest in OLED technology has been impressive and first commercial products based on small molecules and conducting polymer films are already available. The OLED market is still growing and a large expansion in market penetration has been forecasted for the next years [2]. The tremendous interest in OLEDs and displays made from these devices is especially caused by technological aspects such as low costs, the ease of fabrication using standard techniques (e.g. vacuum deposition or solution processing) [9-13], the possibility of realizing flexible or large-area displays, their use in lighting applications and the variety of organic materials providing emission wavelengths that cover wavelengths from the ultraviolet to near infrared [14-16].

Although OLEDs already meet the requirements for some practical applications in, e.g., portable electronics like cellular phones or digital cameras [5] with operating lifetimes up to 100,000 hours [16], the intrinsic limits of organic light-emitting devices have not been reached yet [17]. Therefore, further scientific efforts devoted to the design, engineering and fabrication of OLEDs also considering charge carrier injection, spin effects, interfaces, quenching processes, morphology changes or light extraction have to be undertaken in order to provide a step forward to the complete commercialization of this technology [2]. Because fundamental understanding of the working principle of OLEDs is the crucial prerequisite for the further development of OLED technology, the basic processes occurring in electroluminescent devices are briefly reviewed in this work. Aside from device physics, also the design and synthesis of novel emitter materials plays an important role in commercialization of this technology. Therefore, the concepts of fluorescent and phosphorescent emitter materials are herein discussed putting special focus on phosphorescent iridium complexes (as prototypical example of dopants suitable for realizing high-performance electroluminescent devices).

\section{The working principle of OLEDs}

\subsection{Small molecule OLEDs (smOLEDs) and polymeric light-emitting devices (PLEDs)}

Conventional light-emitting devices commercially available today are mostly made from inorganic crystals such as GaAs or GaN. Although these devices work remarkably well for many applications, their use in large area displays or on flexible substrates is limited or even impossible because of the brittle crystals grown by expensive epitaxial methods [18]. As a consequence, organic materials have soon be considered to be promising alternatives to inorganic semiconductors, however, the practical application of OLEDs was unrealistic due to high operating voltages greater than $100 \mathrm{~V}$ until the fundamental breakthrough of Tang et al. in 1987 [3]. The landmark achievement of a double-layered architecture consisting of a hole transporting layer and an emissive layer of aluminum quinolinolate 
$\left(\mathrm{Alq}_{3}\right)$ gave electroluminescence around $1,000 \mathrm{~cd} \mathrm{~m}^{-2}$ at driving voltages of $10 \mathrm{~V}$ and is still the archetypical setup for OLEDs [19].

Since that time tremendous scientific progress has been made resulting in numerous small molecules suitable for applications in OLEDs (frequently referred to as "small molecule OLEDs", smOLEDs). Because thin films of these emitter materials are usually prepared by vacuum deposition, the interest in organic electroluminescence has further been heightened by the description of electroluminescence from conjugated polymers providing the possibility of solution processing (frequently referred to as "polymeric light-emitting devices", PLEDs) [20]. As a result of this progress, organic semiconductors have developed rapidly from a topic of research interest into a wide range of applications. In this context, considerable advances concerning materials chemistry (e.g. the use of phosphorescent materials to increase device efficiencies) [9], device fabrication and device optimization [21-24] have been made giving OLEDs based on fluorescent small molecules, phosphorescent small molecules as well as polymeric materials (PLEDs) meeting industrial specifications. Although processing techniques are different for smOLEDs and PLEDs, their working principle is basically the same as it is reviewed on the subsequent pages.

\subsection{Single and multilayer OLEDs}

Depending on device architecture, electroluminescent devices can be divided into single layer and multilayer OLEDs. Single layer OLEDs typically consist of a metal cathode with a low work function (e.g. $\mathrm{Ca}, \mathrm{Al}, \mathrm{Ba}$ ), an organic emissive layer and a transparent anode [e.g. indium tin oxide (ITO), which is a nonstoichiometric composite of $\mathrm{SnO}_{2}$ and $\mathrm{In}_{2} \mathrm{O}_{3}$ ] immobilized on a transparent carrier material such as glass or a flexible polymer $[5,25]$. Under action of a driving voltage, electrons are injected from the cathode into the lowest unoccupied molecular orbital (LUMO) of the adjacent organic layer, while the anode injects holes into the highest occupied molecular orbital (HOMO) of the organic material. The electrons and holes move through the organic layer and recombine under the formation of an "exciton" capable of relaxing from its excited state to the ground state by emission of light (cf. Figure 1; here it should be noted that in organic materials mainly hopping transport in disordered materials occurs, whereas band transport mechanisms are typically discussed for inorganic materials) [9]. This process which is referred to as electroluminescence is the basic principle of OLEDs, nevertheless, some critical parameters have to be discussed.

In electroluminescent devices the recombination zone should be in the middle of the emissive layer, thus, an equally efficient injection but also equal mobility of electrons and holes in the organic material are necessary. However, balanced charge injection or carrier mobility is usually not observed in the simple device architecture of single layer OLEDs resulting in decreased efficiencies because of exciton quenching processes close to the electrodes or non-radiative recombination of charges at the electrodes (dark current) [9]. These problems can be overcome by the incorporation of additional layers giving multilayer OLEDs. In these devices the emitter is sandwiched between hole and electron transport layers (cf. Figures 1 and 2) providing facilitated charge injection and enhanced recombination of electrons and holes in the emissive layer shifting the active zone roughly to the middle of the OLED structure. Along this line, state-of-the-art OLEDs have up to five layers, containing charge- and exciton blocking layers being essential for excellent device performance. 
Additionally, it should be mentioned that also doping of the transport levels can readily be used for increasing the efficiencies of the corresponding light-emitting devices [5-7, 9-13].

Figure 1. Energy level scheme of a a) single layer and b) double heterojunction OLED with an applied bias voltage $V$ showing the vacuum energy level $W_{\text {vac }}$, the Fermi levels $W_{\mathrm{F}}$ and work functions $\Phi$ of the metallic contacts (HTL $=$ hole transport layer; EML $=$ emissive layer; ETL = electron transport layer). The level offsets at the organic heterojunction are determined by the ionization energies $I_{\mathrm{S}}$ and electron affinities $A_{\mathrm{S}}$ [9].

a) anode

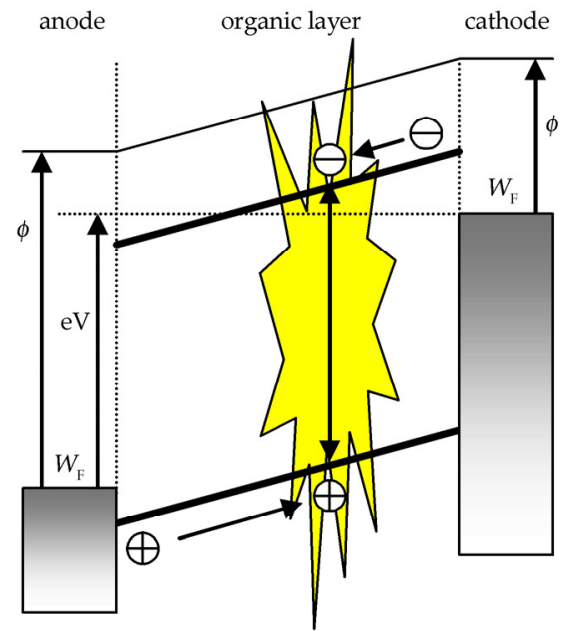

b) anode HTL EML ETL cathode

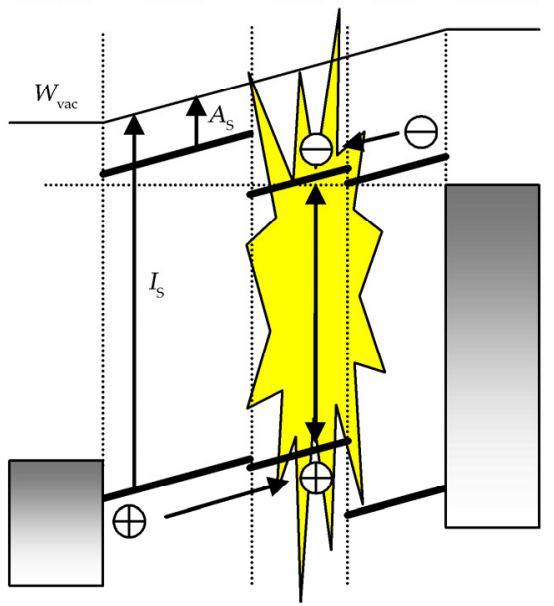

Figure 2. Commonly used a) hole transport (TPD $=N, N^{\prime}$-diphenyl- $N, N$ '-bis (m-tolyl)-1,1'biphenyl-4,4'-diamine; MTDATA $=m$-methyl-tris(diphenylamine)triphenylamine) and b) electron transport materials $\left(\mathrm{Alq}_{3}=\right.$ aluminum quinolinolate; $\mathrm{PBD}=$ (2-(4-biphenyl)-5-(4tert-butylphenyl)-1,3,4-oxadiazol) used in OLEDs [5].

a)<smiles>Cc1cccc(N(c2ccccc2)c2ccc(-c3cccc(N(c4ccccc4)c4ccc(N(c5ccc(N(c6ccccc6)c6cccc(C)c6)cc5)c5ccc(N(c6ccccc6)c6cccc(C)c6)cc5)cc4)c3)cc2)c1</smiles>

b)

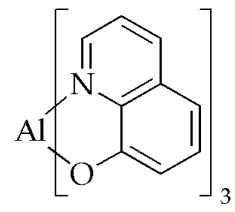

$\mathrm{Alq}_{3}$

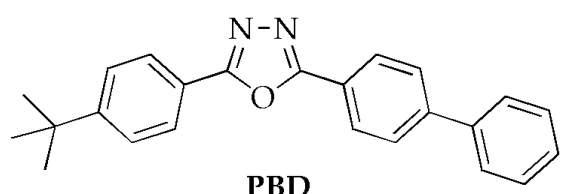

Multilayer devices can be built up either by vacuum sublimation or from solution. While vacuum deposition offers the clear advantage that multilayer structures can be easily realized also providing an 
additional purification step, sublimation processes suffer from a limited number of materials enduring thermal stress. Consequently, solution processing techniques have received considerable attention although serious problems such as orthogonal solvent systems have to be faced. The most convenient strategy to overcome this drawback has yet been proposed by Nuyken et al. applying precursor materials which are converted into insoluble networks by additional crosslinking steps $[5,26]$.

\subsection{Fluorescent and phosphorescent materials in OLEDs}

For efficient OLEDs electrons and holes should form excited states capable of recombining radiatively and without energetic losses. Assuming that balanced charge injection is possible and that all injected charges recombine, considerations on quantum statistics are crucial for the realization of devices exhibiting high efficiencies [14].

Singlet excitons are states with an antisymmetric spin and a total spin quantum number $S=0$. The quantum mechanically allowed transition to the ground state gives rise to fluorescence within nanoseconds. Conversely, triplet states have an even symmetry with $S=1$ whose transition to the singlet ground state is quantum mechanically forbidden resulting in phosphorescence with lifetimes in the microsecond to second regime. As a consequence of the corresponding multiplicities of the angular momentum states (i.e. $m_{S}=0$ for $S=0$ and $m_{S}=-1,0,1$ for $S=1$ ) and the random nature of spin production in electroluminescent devices, simple statistics predicts that only $25 \%$ of the injected charges result fluorescence (from singlet states) whereas $75 \%$ give phosphorescence (from triplet states) in suitable device architectures. Thus, uncorrelated electrons and holes form triplet states with a threefold higher probability than singlet states [9]. Here it should be noted, that recent studies on spin statistics suggest variations in the singlet-to-triplet-ratios. These findings have also been confirmed by quantum mechanical calculations [11].

The ground states of most luminescent materials are singlet states and the vast majority of luminescent compounds exhibits only weak spin-orbit couplings rendering these small molecules and polymers fluorescent with negligible radiative rates from triplet states. Competing nonradiative processes (e.g. triplet-triplet annihilation or vibronic relaxation) effectively quench the phosphorescence of the associated excited states clearly limiting the maximum quantum efficiency achievable with fluorescent small molecules and polymeric materials [14].

Since the pioneering work of Baldo et al. showing that phosphorescent dyes (transition metal compounds with organic ligands or organometallic compounds) doped into appropriate host materials give improved OLEDs [27], considerable scientific efforts have provided numerous new materials for electrophosphorescent devices reaching impressive external quantum efficiencies. Although these devices usually require elaborated multilayer structures, the fast and efficient intersystem crossing (ISC) from excited singlet to light-emitting triplet states caused by strong spin-orbit couplings as well as the ability of triplet harvesting allow theoretically quantum efficiencies of $100 \%$ [14, 25]. Today, a huge number of phosphorescent dyes are used in phosphorescent OLEDs utilizing different metal complexes containing transition metals such as iridium, platinum, osmium, ruthenium, etc. [28-30]. These transition metal complexes definitely exhibit a series of very desirable materials properties such as emission wavelengths covering the entire visible spectrum, high quantum yields and long lifetimes, however, severe concentration quenching is observed for most pure layers of phosphorescent dyes 
[31]. Consequently, phosphorescent dyes are usually blended into suitable host materials (small molecules or polymers) from which the excitation energy is transferred to the phosphorescent guest [14]. Thus, basic knowledge about the energy transfer processes is required for understanding the working principle of phosphorescent OLEDs.

\subsection{Transfer processes in host materials doped with phosphorescent dyes}

The transfer of excitation energy to the guest is promoted by three processes (cf. Figure 3), namely long-range Förster transfer of singlet excitons generated on the matrix to the guest, short-range Dexter transfer of singlet and triplet excitons generated on the host to the dopant and direct generation of singlet and triplet excitons on the guest (in this case the host solely acts as charge-transporting matrix). While for the Förster transfer a significant overlap of the emission spectrum of the matrix and the absorption spectrum of the guest is a crucial parameter, efficient Dexter transfer, on the other hand, requires that the energies of the singlet and triplet excitons on the host match the exciton energies on the guest. Also for direct carrier trapping on the phosphorescent dye a significant offset of the HOMO and LUMO energies of the host and guest material is necessary as schematically depicted in Figure 3 (here it should be noted that OLEDs are more efficient if the charges are trapped on the phosphorescent emitter. If Förster transfer is necessary, a loss in power efficiency is found because of host population processes) [14].

Figure 3. Simplified illustration of different transfer processes from the host to the guest. Direct electron/hole transfer from the host LUMO/HOMO to the guest LUMO/HOMO, Förster energy transfer between singlet states and Dexter energy transfer from the host to the guest triplet states are shown [14].

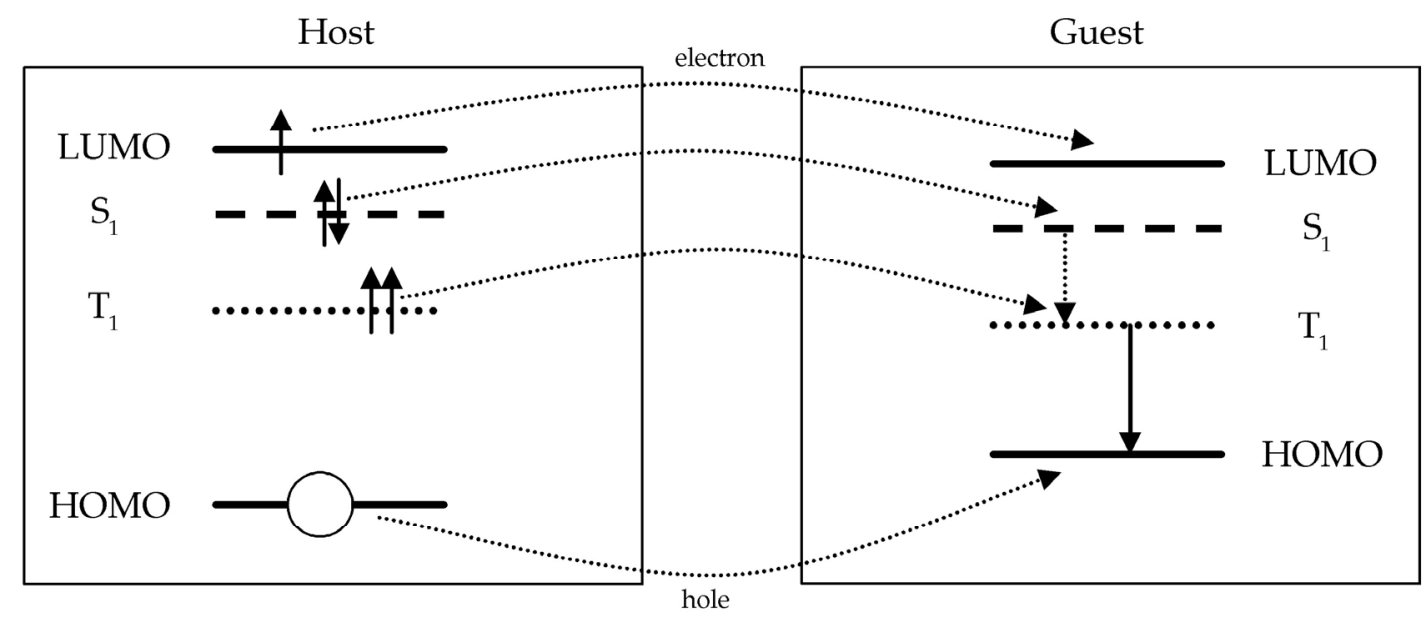

Irrespective which process results the excitation of the phosphorescent dye in an electrophosphorescent OLED, efficient triplet harvesting on the transition metal complex is only guaranteed if the $T_{1}-S_{0}$ energy of the guest is smaller than that of the host. Therefore, only a limited number of suitable host materials is known for most phosphorescent compounds also pointing out the need for new small molecules and polymeric materials capable of excitation of red, green and blue phosphors [14]. Although the processes giving electrophosphorescence are basically understood, large 
scientific efforts are ongoing studying the concomitant excitation routes in OLEDs. Excellent reviews on this topic have been published recently $[14,25]$.

\subsection{Host materials for phosphorescent OLEDs}

For the fabrication of efficient phosphorescent OLEDs, the transition metal complex is typically used as emitting guest in a host material to avoid triplet-triplet annihilation or quenching effects associated with the relatively long excited state lifetimes. Thus, the synthesis and characterization of adequate host materials are of significant importance and provide big challenges for chemists [32].

In general, a prerequisite for suitable host materials is that the triplet level of the host is larger than the triplet level of the phosphorescent guest for preventing undesired energy back transfer processes [32]. In addition to the match of the host and guest triplet states, also HOMO/LUMO levels permitting good charge injection as well as chemical and morphological stability of the host are critical parameters [33]. Furthermore, considerable overlaps between the absorption bands of the guest and the emission spectrum of the host are very desirable providing efficient Förster transfer [34]. Among the studied materials, only some classes fulfill the above mentioned boundary conditions. Especially carbazoles, polyphenylenes and fluorenes (small molecules as well as polymers; note that the $\mathrm{T}_{1}$-levels of, e.g., polyfluorenes are too low for being adequate host materials except for red triplet emitters) are of special interest because they are able to host red, green and even blue triplet emitters (cf. Figure 4) [35-49].

Figure 4. Selected examples of host materials for phosphorescent iridium(III) complexes [32-48].
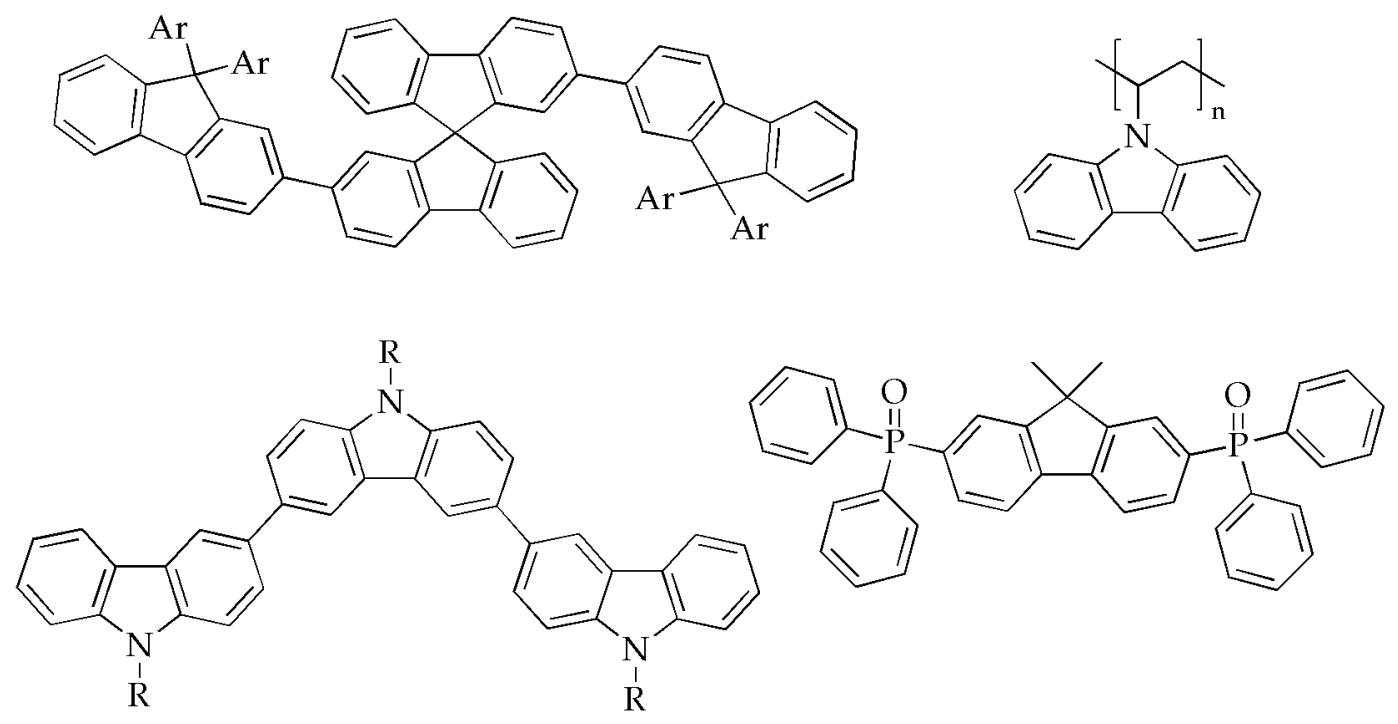

\subsection{Advantages of OLEDs in display technology}

The development of OLEDs in the last decades has shown that organic electroluminescence is a viable display principle for different fields of application [4]. Due to the very desirable materials properties of fluorescent and phosphorescent small molecules as well as semiconducting polymers (e.g. permitting vacuum deposition or solution processing) [18], the inexpensive manufacturing of 
pixilated displays has provided electroluminescent displays including the advantages of wide viewing angles, fast display response times in the microsecond regime, broad color ranges, high dark contrasts and thin display modules. Furthermore, OLEDs definitely provide numerous advantages such as high image quality or high power efficiency [4].

Even though it can be argued that liquid crystal or plasma displays exhibit similar or even superior properties especially concerning materials stability and longevity, the use of OLEDs offers some distinct new possibilities which are not accessible with other approaches. Among them, top and bottom emitting transparent OLEDs (TOLEDs) for, e.g., head-up displays, full color displays prepared from stacked red, green and blue subpixels, or OLED displays fabricated on flexible substrates are just few selected examples of promising fields of application of this technology [9].

In the context of further development of OLEDs for practical applications in display technology, particularly phosphorescent emitter materials have earned considerable attention because of the above discussed reasons (e.g. external quantum efficiencies, etc.). Not surprisingly, numerous reports can be found in literature focusing on the synthesis and characterization of novel iridium, platinum or osmium based complexes for realizing highly efficient phosphorescent OLEDs [28, 30, 50, 51]. Among these materials, phosphorescent iridium(III) complexes are anticipated to be the most promising candidates for practical applications. Therefore, we herein focus on this kind of phosphor briefly reviewing the different synthesis procedures and photophysical properties of homo- and heteroleptic iridium(III) complexes.

\section{Phosphorescent iridium(III) complexes}

\subsection{Synthesis of iridium(III) complexes}

The interest in iridium compounds (iridium(I) and iridium(III) species) has especially been boosted by the different fields of application ranging from very efficient catalysts to important emitter materials in OLEDs. Although the catalytic activity of iridium complexes has been well-known for a significant period of time [52], a new era of utilization has commenced its rapid development with the first reports on electrophosphorescent devices [27]. In particular, the very desirable materials properties such as reversible electrochemistry, adequate triplet lifetimes, synthetic versatility, colortuning of the emission wavelengths by ligand modifications or the robust nature of many iridium(III) complexes render these compounds ideal candidates for the fabrication of highly efficient phosphorescent OLEDs [53-55]. Neutral electrophosphorescent iridium(III) compounds are definitely the most common phosphorescent dopants in OLEDs distinguishing two classes, namely homoleptic compounds containing three cyclometalating ligands and heteroleptic iridium complexes with two cyclometalating ligands and an ancillary ligand. Nevertheless intense studies on neutral iridium complexes are topic of worldwide scientific efforts, also charged derivatives receive more and more attention due to possible applications in light-emitting electrochemical cells (LECs) [56].

For the preparation of these compounds usually the "bridge-splitting" approach is used. In this synthesis strategy the cyclometalating ligand (e.g. phenylpyridine, benzoquinoline, 2-phenylbenzothiazole, etc.) is reacted with $\mathrm{IrCl}_{3} \cdot \mathrm{nH}_{2} \mathrm{O}$ in 2-ethoxyethanol under inert atmosphere giving the corresponding air-stable $\mu$-chloro bridged precursor material as reported by Nonoyama (cf. Scheme 1) [57]. Although this procedure is widely used, alternative protocols performing the 
cyclometalation reaction in trimethyl phosphate at significantly lower temperatures have been reported [58].

Scheme 1. Preparation of the $\mu$-chloro bridged precursor material di- $\mu$-chloro-tetrakis$\left(\kappa^{2}\left(C^{2}, N\right)\right.$-2-phenylpyridine)diiridium(III) as reported by Nonoyama [57].

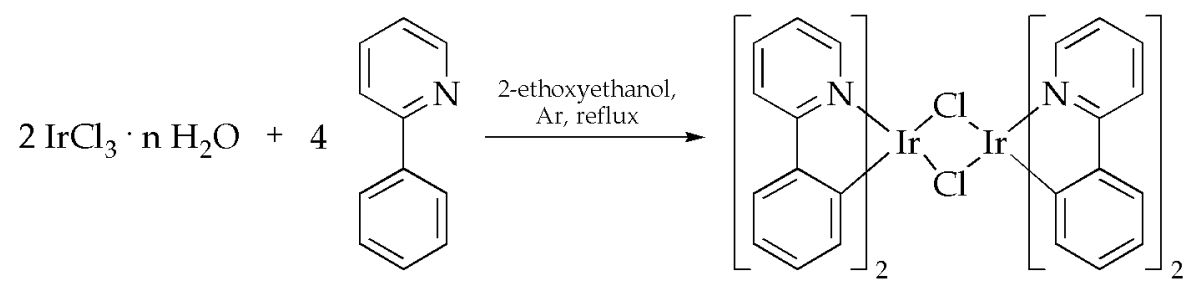

The first report on homoleptic tris-cyclometalated iridium(III) compounds was published in the early 1980s being observed as a byproduct of the synthesis of di- $\mu$-chlorotetrakis $\left(\kappa^{2}\left(C^{2}, N\right)\right.$-2-phenylpyridine)diiridium(III) [59]. Since that time and enforced by the excellent electroluminescent properties of e.g. $\operatorname{Ir}(\mathrm{ppy})_{3}$ (ppy $=$ phenylpyridine) as well as the possibility of efficient color-tuning by simple changes or modifications of the cyclometalating ligand, numerous optimized protocols have been presented giving tris-cyclometalated complexes in acceptable yields. Among them, ligandexchange reactions starting from $\operatorname{Ir}(\mathrm{acac})_{3}$, solvent-free procedures or approaches conducted at high temperatures of $170-195^{\circ} \mathrm{C}$ in the presence of silver triflates have been proposed (cf. Scheme 2) [55]. However, the harsh reaction conditions, comparable low yields and the number of byproducts [60] are considered to be significant drawbacks of homoleptic iridium complexes. Additionally, the rate of formation of the facial and meridional isomer was found to be influenced by the reaction conditions. It is worth noting that these coordination isomers exhibit different photophysical properties [61-63] and undergo isomerization processes in, e.g., working electroluminescent devices [55]. From aluminum quinolinolates it is well known that such effects give undesired changes of the device characteristics [64], therefore, this is considered to be another shortcoming of homoleptic iridium compounds.

Scheme 2. Different synthetic routes for the preparation of tris-cyclometalated iridium(III) complexes [55].
a) $\operatorname{Ir}(\mathrm{acac})_{3}+3 \mathrm{C}^{\wedge} \mathrm{NH}$
$\stackrel{\text { glycerol, } \mathrm{N}_{2} \text {, reflux }}{\longrightarrow} \operatorname{Ir}\left(\mathrm{C}^{\wedge} \mathrm{N}\right)_{3}+3 \mathrm{acacH}$
b) $\left(\mathrm{C}^{\wedge} \mathrm{N}\right)_{2} \operatorname{Ir}\left(\mathrm{O}^{\wedge} \mathrm{O}\right)+\mathrm{HC}^{\wedge} \mathrm{N}$
$\stackrel{\text { glycerol, } \mathrm{N}_{2} \text {, reflux }}{\longrightarrow} \operatorname{Ir}\left(\mathrm{C}^{\wedge} \mathrm{N}\right)_{3}+\mathrm{O}^{\wedge} \mathrm{OH}$
c) $\left[\left(\mathrm{C}^{\wedge} \mathrm{N}\right)_{2} \mathrm{IrCl}\right]_{2}+2 \mathrm{HC}^{\wedge} \mathrm{N}$
$\underset{\mathrm{K}_{2} \mathrm{CO}_{3}}{\stackrel{\text { glycerol, } \mathrm{N}_{2} \text {, reflux }}{\longrightarrow}}$
$2 \operatorname{Ir}\left(\mathrm{C}^{\wedge} \mathrm{N}\right)_{3}+2 \mathrm{KCl}+\mathrm{H}_{2} \mathrm{O}+\mathrm{CO}_{2}$

$$
\begin{aligned}
& \mathrm{O}^{\wedge} \mathrm{O}=\text { ancillary ligand } \\
& \mathrm{C}^{\wedge} \mathrm{N}=\text { cyclometalating ligand }
\end{aligned}
$$

In contrast to the difficulties with the preparation of tris-cyclometalated iridium complexes, an alternative synthesis approach is based on incorporating ancillary ligands such as acetylacetonates (cf. Figure 4), picolinates, triazolates, tetrazolates or quinolinolates [65-67]. Although the preparation of heteroleptic iridium(III) compounds starts, again, from the corresponding $\mu$-chloro bridged 
precursor materials, the subsequent bridge-splitting step is clearly facilitated giving the products in better or even quantitative yields. However this is a distinct advantage, only few successful examples of heteroleptic iridium compounds with emission properties dominated by these ligands have been reported [65]. Thus, color-tuning is usually achieved by changing the nature of the cyclometalating ligand but, on the other hand, requires the synthesis of different precursors [55, 68]. Nevertheless this is considered to be a significant drawback of this approach, many heteroleptic iridium complexes bearing ancillary ligands exhibit very desirable materials properties such as high quantum yields even at room temperature or good thermal stabilities providing the possibility of vacuum deposition processes. As a consequence, they are frequently used as phosphorescent dopants in OLEDs [68-70].

Figure 4. Schematic representation of a heteroleptic iridium(III) complex bearing an ancillary acac ligand [55].

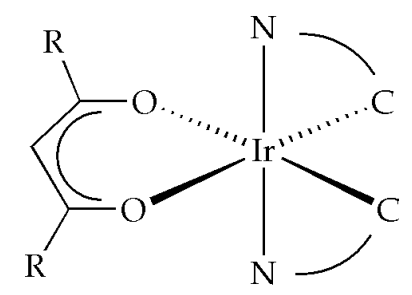

\subsection{Photophysical properties of iridium(III) complexes}

Tuning of the photophysical properties of iridium(III) complexes has received considerable attention because of a series of practical applications such as flat-panel displays. Even though numerous organoiridium compounds have been reported giving efficient electroluminescence in the red [68], green [55] and blue spectral region [71-77], further scientific efforts are necessary to provide a general toolbox for realizing iridium compounds with absorption and emission characteristics tailored towards particular needs [53, 78]. In this context, numerous reports on the synthesis and photophysical characterization of novel iridium(III) complexes have been published [53, 55, 78], but also quantum mechanical calculations are becoming more and more important in the design of phosphorescent emitter materials [79-83].

The absorption and emission spectra of phosphorescent metal complexes are in general influenced by various parameters such as the valence electron configuration at the metal, the type of the electronic transitions or the correlation among lower lying electronic excited states [78]. Similar to fluorescent small molecules also the photophysical behavior of transition metal complexes can be properly described with molecular orbitals, however, the performance of accurate quantum mechanical calculations is far more complicated [79]. Nevertheless, it has been shown that frontier molecular orbitals are not equally delocalized in heavy metal complexes resulting in different electronically excited states [78].

Among them, metal-centered (MC) excited states are typically present in metal complexes with partially filled $\mathrm{d}$ shells at the metal center. The corresponding $\mathrm{d}$-d transitions are Laporte-forbidden and, consequently, exhibit very low transition probabilities. Metal-to-ligand charge-transfer (MLCT) states involve electronic transitions from metal based $d$ orbitals to a ligand centered $\pi^{*}$ antibonding orbital. Emissive MLCT states are particularly observed in $\mathrm{d}^{6}$ and $\mathrm{d}^{8}$ transition metal complexes and 
play, therefore, a major role in the photophysics of iridium(III) compounds. Intraligand (IL) $\pi-\pi^{*}$ excited states originate from electronic transitions of the ligand. If the metal perturbation upon coordination is minimized, their spectral properties often closely resemble the free ligand states. Finally, ligand-to-metal charge transfer (LMCT) excited states are occasionally observed in complexes with metal atoms in high oxidation states or in $\mathrm{d}^{10}$ complexes [28, 78, 79].

All these transitions determine the photophysical properties of transition metal complexes and can be used for the interpretation of experimentally observed spectra or prediction of absorption and emission characteristics of novel compounds [28, 78, 79]. Hence, this elementary knowledge of the described processes is necessary to rationalize the impact of ligand modifications on the photophysical properties of phosphorescent dyes or to design highly efficient materials for OLED applications.

Along these lines, the absorption spectra of classical phosphorescent iridium(III) complexes typically display absorption bands with extinction coefficients between approximately 50000 and 6000 $\mathrm{L} \mathrm{mol}^{-1} \mathrm{~cm}^{-1}$ (cf. Figure 5 as a typical example). The weak absorption features between 500 and 350 $\mathrm{nm}$ can be attributed to spin-allowed and spin-forbidden metal-to-ligand charge-transfer (MLCT) transitions, while the strong absorption bands peaking in the UV-region usually originate from intraligand (IL) $\pi-\pi^{*}$ transitions $[14,73]$.

Figure 5. The absorption spectra of iridium(III) compounds typically show MLCT and $\pi$ $\pi^{*}$ transitions. Here the spectrum of $\operatorname{bis}\left(\kappa^{2}\left(C^{2}, N\right)-2-\right.$ phenylpyridine $)\left(\kappa^{2}(N, O)-8-\right.$ quinolinolate)iridium(III) is shown [67].

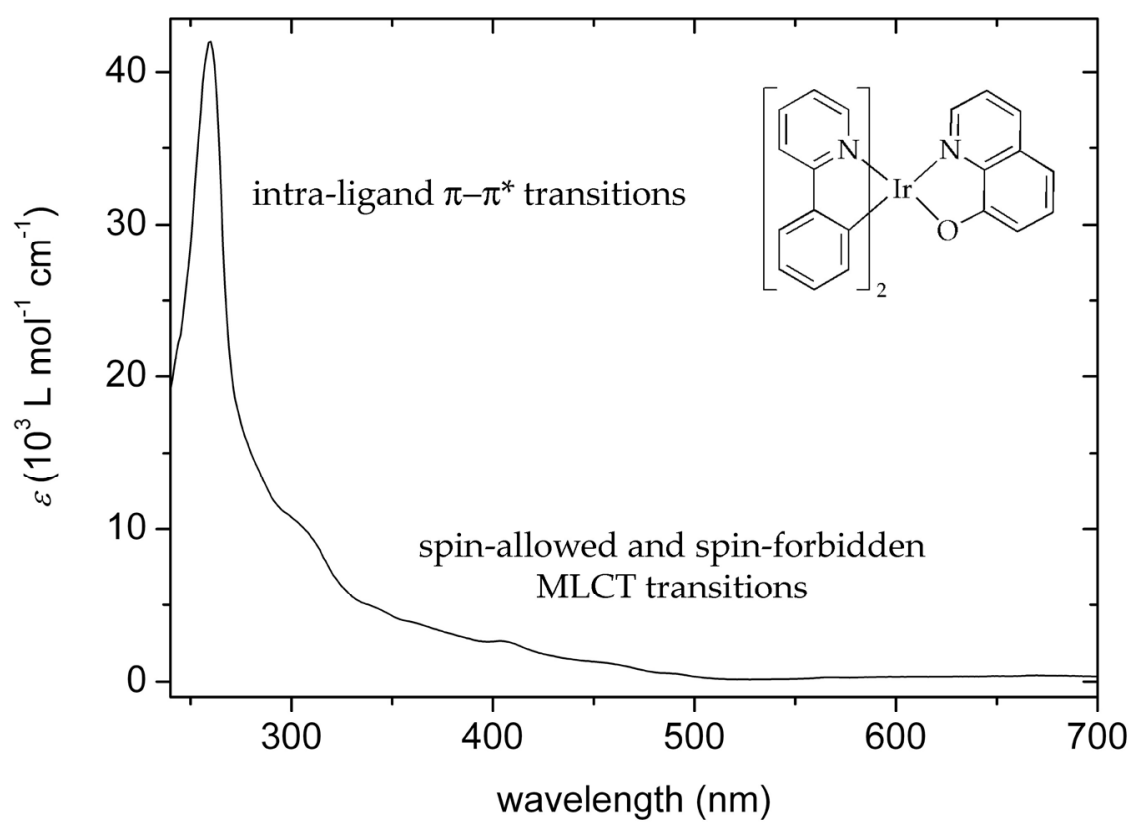

After excitation of the iridium complex, the strong spin-orbit coupling induced by the metal center gives the formally forbidden triplet to singlet ground state transition a significant allowedness [14]. In this context, the energies of the lowest excited states play a major role as they can be tuned by adjusting the metal and ligand orbitals through substituent effects or via changing the ligand structures (some frequently used cyclometalating and ancillary ligands are shown in Figure 6). In other words, chemical modifications and/or complete alterations of the cyclometalating and/or ancillary ligands 
pave the way to very efficient emission color tuning but also provide the possibility of tuning the corresponding absorption characteristics towards particular needs [66, 67].

Figure 6. Commonly used a) cyclometalating and b) ancillary ligands for homo- and heteroleptic iridium(III) complexes [28, 53, 55, 78, 79].

a)<smiles>c1ccc(-c2ccccn2)cc1</smiles><smiles>c1ccc(-c2cccs2)nc1</smiles><smiles>c1ccc(-c2cc3ccccc3s2)nc1</smiles>

b)<smiles>CC(=O)CC(C)=O</smiles><smiles>O=C(O)c1ccccn1</smiles><smiles>c1ccc(-c2ccc3ccccc3n2)cc1</smiles><smiles>c1ccc2ncccc2c1</smiles>

Tremendous emission color-versatility has been achieved with iridium(III) luminophores applying the above described tuning procedures giving materials with a broad range of excited state lifetimes (from nanoseconds to microseconds; here it should be noted that a long lifetime will increase the probability of excited state quenching processes and increases diffusion of the excited state, which will in turn call for efficient concepts to confine the excitation in the emissive layer) and quantum yields approaching 100\% [53]. As a consequence, phosphorescent iridium complexes have emerged as the most promising class for practical OLED applications and the number of new phosphorescent dyes with emission wavelengths covering the entire visible spectrum is still growing. Some selected examples of organoiridium complexes emitting in the blue, green and red spectral region are depicted in Figure 7. A more detailed summary of various iridium complexes and their photophysical characteristics can be found elsewhere [28, 53, 55, 68-79].

Figure 7. Selected examples of phosphorescent iridium complexes with emission maxima in the blue, green and red spectral region $[68,71]$.<smiles></smiles>

emitting at $455 \mathrm{~nm}$

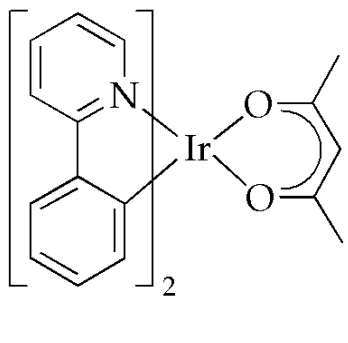

emitting at $516 \mathrm{~nm}$

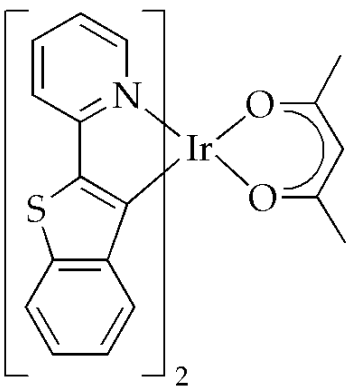

emitting at $612 \mathrm{~nm}$ 


\subsection{Polymeric phosphorescent materials}

Even though many phosphorescent dyes are very promising candidates for realizing highly efficient OLEDs, for numerous phosphorescent small molecules serious problems such as the complexity of device fabrication or insufficient fine-dispersion of the dopant in the host material have been encountered. Especially phase separation is concerned as critical drawback, thus, covalent incorporation of the phosphorescent chromophores into polymers has received considerable attention.

Figure 8. Selected examples of precursor materials for different polymerization techniques [84-102].
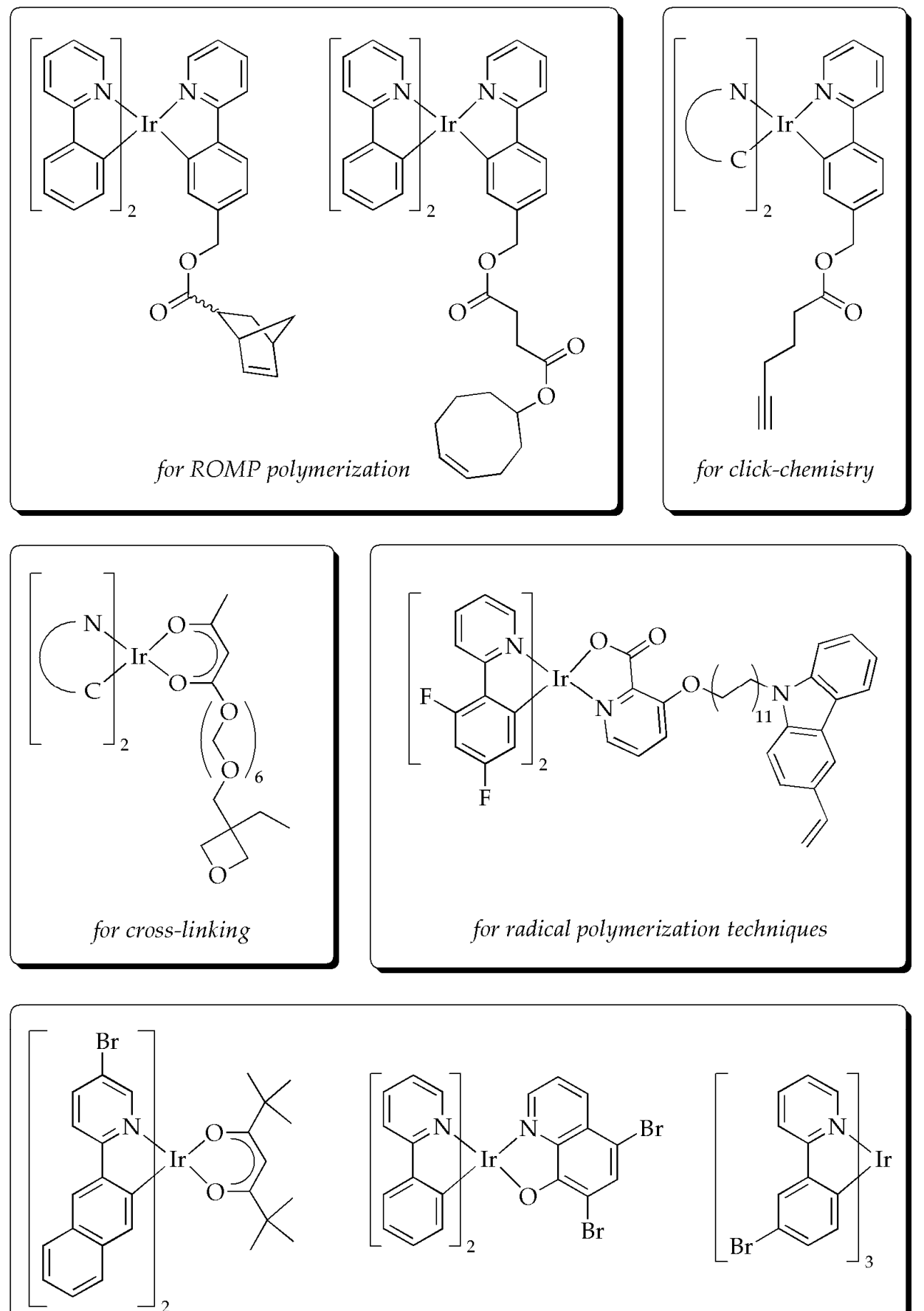

for Suzuki or Yamamoto polymerization techniques 
As a result, numerous concepts for the preparation of phosphorescent polymers have been proposed, among them utilization of ring-opening metathesis polymerization (ROMP), click-chemistry, the use of cross-linkable iridium complexes, grafting approaches or radical polymerization techniques [84-96]. In addition to these methods giving side-chain polymers, the incorporation of the phosphorescent material in the main-chain using various cross-coupling reactions is of particular interest for realizing solution processable emitter materials (some selected examples of precursor materials for the preparation of phosphorescent polymers are shown in Figure 8) [97-102]. Indeed, all these approaches have been demonstrated to overcome the shortcomings of phosphorescent small molecules and are, therefore, believed to contribute significantly to the further development of OLED technology.

\section{Conclusions and Outlook}

Herein the essentials of OLED technology have been reviewed putting special focus on the working principle of single and multilayer OLEDs as well as the use of fluorescent and phosphorescent emitter materials. After discussion of the advantages of phosphorescent dyes doped into suitable host materials and the corresponding energy transfer processes, the synthesis and photophysical properties of phosphorescent iridium(III) complexes have been enclosed. It has been shown that this class of materials exhibits photophysical characteristics readily tuned by changes of the cyclometalating and/or ancillary ligands, thus being ideal candidates for applications in, e.g., full color displays. Furthermore, different strategies for incorporating iridium complexes into polymers have been presented giving phosphorescent polymers with reduced phase separation in combination with facilitated device fabrication (e.g. solution processing).

The development of OLEDs has undoubtedly been empowered by different applications in display technology. As a consequence, tremendous scientific efforts have been devoted to this topic concentrating on the design, engineering and fabrication of OLEDs. Nevertheless, the intrinsic limits of OLED technology have not been reached yet. Hence, further progress in device physics and materials science is necessary to provide a step forward to the complete commercialization of this highly promising technology.

\section{Acknowledgements}

Financial support by the Austrian Science Fund in the framework of the Austrian Nano Initiative RPC ISOTEC - RP 0701 and 0702 is gratefully acknowledged.

\section{References}

1. Pope, M.; Kallmann, H.; Magnante, P. Electroluminescence in Organic Crystals. J. Chem. Phys. 1963, 38, 2042-2043.

2. Vardeny, Z.V.; Heeger, A.J.; Dodabalapur, A. Fundamental Research Needs in Organic Electronic Materials. Synth. Met. 2005, 148, 1-3.

3. Tang, C.W.; VanSlyke, S.A. Organic Electroluminescent Diodes. Appl. Phys. Lett. 1987, 51, 913-915. 
4. Haskal, E.I.; Büchel, M.; Duineveld, P.C.; Sempel, A.; van de Weijer, P. Passive-Matrix Polymer Light-Emitting Displays. MRS Bull. 2002, 864-869.

5. Nuyken, O.; Jungermann, S.; Wiederhirn, V.; Bacher, E.; Meerholz, K. Modern Trends in Organic Light-Emitting Devices (OLEDs). Monatsh. Chem. 2006, 137, 811-824.

6. Kido, J.; Matsumoto, T. Bright Organic Electroluminescent Devices Having a Metal-doped Electron-injecting Layer. Appl. Phys. Lett. 1998, 73, 2866-2868.

7. Walzer, K.; Maennig, B.; Pfeiffer, M.; Leo, K. Highly Efficient Organic Devices Based on Electrically Doped Transport Layers. Chem. Rev. 2007, 107, 1233-1271.

8. Sović, T.; Kappaun, S.; Koppitz, A.; Zojer, E.; Saf, R.; Bartl, K.; Fodor-Csorba, K.; Vajda, A.; Diele, S.; Pelzl, G.; Slugovc, C.; Stelzer, F. Main-Chain Liquid Crystalline Polymers Based on Bis-Etherified 9,9-Dihexyl-2,7-bis(40-hydroxy-1,10-biphen-4-yl)fluorenes. Macromol. Chem. Phys. 2007, 208, 1458-1468.

9. Waser, R., Ed. Nanoelectronics and Information Technology-Advanced Electronic Materials and Novel Devices; Wiley-VCH: Weinheim, 2003; p. 917.

10. Blom, P.W.M.; Tanase, C.; de Leeuw, D.M.; Coehoorn, R. Thickness Scaling of the Spacecharge-limited Current in poly(p-phenylene vinylene). Appl. Phys. Lett. 2005, 86, 092105092105-3.

11. Wohlgenannt, M.; Tandon, K.; Mazumdar, S.; Ramasesha, S.; Vardeny, Z.V. Formation Crosssections of Singlet and Triplet Excitons in $\pi$-conjugated Polymers. Nature 2001, 409, 494-497.

12. Köhler, A.; Wilson, J.S.; Friend, R.H. Fluorescence and Phosphorescence in Organic Materials. Adv. Mater. 2002, 14, 701-707.

13. Shuai, Z.; Beljonne, D.; Silbey, R.J.; Brédas, J.L. Singlet and Triplet Exciton Formation Rates in Conjugated Polymer Light-Emitting Diodes. Phys. Rev. Lett. 2000, 84, 131-134.

14. Yang, X.; Neher, D. Polymer Electrophosphorescence Devices. In Organic Light-Emitting Devices; Müllen, K., Scherf, U., Eds.; Wiley-VCH: Weinheim, 2006; p. 333.

15. Kido, J.; Kimura, M.; Nagai, K. Multilayer White Light-Emitting Organic Electroluminescent Device. Science 1995, 267, 1332-1334.

16. Campbell, I.H.; Crone, B.K.; Smith, D.L. Physics of Organic Light-Emitting Diodes. In Semiconducting Polymers; Hadziioannou, G., Malliaras, G.G., Eds.; Wiley-VCH: Weinheim, 2007; p. 421.

17. Sheats, J.R. Manufacturing and Commercialization Issues in Organic Electronics. J. Mater. Res. 2004, 19, 1974-1989.

18. Gong, X.; Moses, D.; Heeger, A.J. Polymer-Based Light-Emitting Diodes (PLEDs) and DisplaysFabrication from Arrays of PLEDs. In Semiconducting Polymers; Hadziioannou, G., Malliaras, G.G., Eds.; Wiley-VCH: Weinheim, 2007; p. 151.

19. Fung, M.-K.; Lee, C.-S.; Lee, S.-T. Metal/Polymer Interface Studies for Organic Light-Emitting Devices. In Organic Light-Emitting Devices; Müllen, K., Scherf, U., Eds.; Wiley-VCH: Weinheim, 2006; p. 181.

20. Burroughes, J.H.; Bradley, D.D.C.; Brown, A.R.; Marks, R.N.; Mackay, K.; Friend, R.H.; Burns, P.L.; Holmes, A.B. Light-emitting Diodes Based on Conjugated Polymers. Nature 1990, 347, 539-541. 
21. Lu, J.; Jin, Y.; Ding, J.; Tao, Y.; Day, M. High-efficiency Multilayer Polymeric Blue Lightemitting Diodes Using Boronate Esters as Cross-linking Linkages. J. Mater. Chem. 2006, 16, 593-601.

22. Lim, S.C.; Kim, S.H.; Chu, H.Y.; Lee, J.H.; Lee, J.-I.; Oh, J.Y.; Kim, D.; Zyung, T. New Method of Driving an OLED with an OTFT. Synth. Met. 2005, 151, 197-201.

23. Shao, Y.; Yang, Y. Organic Solid Solutions: Formation and Applications in Organic LightEmitting Diodes. Adv. Funct. Mater. 2005, 15, 1781-1786.

24. Smith, L.H.; Wasey, J.A.E.; Samuel, I.D.W.; Barnes, W.L. Light Out-Coupling Efficiencies of Organic Light-Emitting Diode Structures and the Effect of Photoluminescence Quantum Yield. Adv. Funct. Mater. 2005, 15, 1839-1844.

25. Yersin, H. Triplet Emitters for OLED Applications. Mechanisms of Exciton Trapping and Control of Emission Properties. Top. Curr. Chem. 2004, 241, 1-26.

26. Meerholz, K.; Müller, C.-D.; Nuyken, O. Crosslinkable Organic Semiconductors for Use in Organic Light-Emitting Diodes (OLEDs). In Organic Light-Emitting Devices; Müllen, K., Scherf, U., Eds.; Wiley-VCH: Weinheim, 2006; p. 293.

27. Baldo, M.A.; O’Brien, D.F.; You, Y.; Shoustikov, A.; Sibley, S.; Thompson, M.E.; Forrest, S.R. Highly Efficient Phosphorescent Emission from Organic Electroluminescent Devices. Nature 1998, 395, 151-154.

28. Evans, R.C.; Douglas, P.; Winscom, C.J. Coordination Complexes Exhibiting Room-temperature Phosphorescence: Evaluation of Their Suitability as Triplet Emitters in Organic Light Emitting Diodes. Coord. Chem. Rev. 2006, 250, 2093-2126.

29. Tsuboi, T.; Aljaroudi, N. Electronic Relaxation Processes in the T1 State of Phosphorescent factris(2-phenylpyridine) Iridium Molecule in 4,4'-N,N'-dicarbazole-biphenyl Host. Jpn. J. Appl. Phys. 2008, 47, 1266-1270.

30. Hertel, D.; Müller, C.D.; Meerholz, K. Organische Leuchtdioden: Bilderzeugung. Chem. Unserer Zeit 2005, 39, 336-347.

31. Wang, Y.; Herron, N.; Grushin, V.V.; LeCloux, D.; Petrov, V. Highly Efficient Electroluminescent Materials Based on Fluorinated Organometallic Iridium Compounds. Appl. Phys. Lett. 2001, 79, 449-451.

32. Wong, K.-T.; Chen, Y.-M.; Lin, Y.-T.; Su, H.-C.; Wu, C.-C. Nonconjugated Hybrid of Carbazole and Fluorene: A Novel Host Material for Highly Efficient Green and Red Phosphorescent OLEDs. Org. Lett. 2005, 7, 5361-5364.

33. van Dijken, A.; Bastiaansen, J.J.A.M.; Kiggen, N.M.M.; Langeveld, B.M.W.; Rothe, C.; Monkman, A.; Bach, I.; Stössel, P.; Brunner, K. Carbazole Compounds as Host Materials for Triplet Emitters in Organic Light-Emitting Diodes: Polymer Hosts for High-Efficiency LightEmitting Diodes. J. Am. Chem. Soc. 2004, 126, 7718-7727.

34. Zhu, W.; Mo, Y.; Yuan, M.; Yang, W.; Cao, Y. Highly Efficient Electrophosphorescent Devices Based on Conjugated Polymers Doped with Iridium Complexes. Appl. Phys. Lett. 2002, 80, $2045-$ 2047.

35. Brunner, K.; van Dijken, A.; Börner, H.; Bastiaansen, J.J.A.M.; Kiggen, N.M.M.; Langeveld, B.M.W. Carbazole Compounds as Host Materials for Triplet Emitters in Organic Light-Emitting 
Diodes: Tuning the HOMO Level without Influencing the Triplet Energy in Small Molecules. $J$. Am. Chem. Soc. 2004, 126, 6035-6042.

36. Chen, Y.-C.; Huang, G.-S.; Hsiao, C.-C.; Chen, S.-A. High Triplet Energy Polymer as Host for Electrophosphorescence with High Efficiency. J. Am. Chem. Soc. 2006, 128, 8549-8558.

37. King, S.M.; Al-Attar, H.A.; Evans, R.J.; Congreve, A.; Beeby, A.; Monkman, A.P. The Use of Substituted Iridium Complexes in Doped Polymer Electrophosphorescent Devices: The Influence of Triplet Transfer and Other Factors on Enhancing Device Performance. Adv. Funct. Mater. 2006, 16, 1043-1050.

38. Vecchi, P.A.; Padmaperuma, A.B.; Qiao, H.; Sapochak, L.S.; Burrows, P.E.A DibenzofuranBased Host Material for Blue Electrophosphorescence. Org. Lett. 2006, 8, 4211-4214.

39. Lin, C.-H.; Chang, Y.-T.; Li, C.-S.; Liu, C.-H.; Duan, J.-P. Bis(arylquinoxalinyl)carbazole Derivatives as Saturated Blue Emitters for Electroluminescent Devices. Synth. Met. 2006, 156, 671-676.

40. Tsai, M.-H.; Lin, H.-W.; Su, H.-C.; Ke, T.-H.; Wu, C.-c.; Fang, F.-C.; Liao, Y.-L.; Wong, K.-T.; $\mathrm{Wu}$, C.-I Highly Efficient Organic Blue Electrophosphorescent Devices Based on 3,6Bis(triphenylsilyl)carbazole as the Host Material. Adv. Mater. 2006, 18, 1216-1220.

41. Padmaperuma, A.B.; Sapochak, L.S.; Burrows, P.E. New Charge Transporting Host Material for Short Wavelength Organic Electrophosphorescence: 2,7-Bis(diphenylphosphineoxide)-9,9dimethylfluorene. Chem. Mater. 2006, 18, 2389-2396.

42. Gong, X.; Ostrowski, J.C.; Moses, D.; Bazan, G.C.; Heeger, A.J. High-performance Polymerbased Electrophosphorescent Light-emitting Diodes. J. Polym. Sci., Part B: Polym. Phys. 2003, 41, 2691-2705.

43. Li, Y.; Ding, J.; Day, M.; Tao, Y.; Lu, J.; D'iorio, M. Synthesis and Properties of Random and Alternating Fluorene/Carbazole Copolymers for Use in Blue Light-Emitting Devices. Chem. Mater. 2004, 16, 2165-2173.

44. Diaz, J.L.; Dobarro, A.; Villacampa, B.; Velasco, D. Structure and Optical Properties of 2,3,7,9Polysubstituted Carbazole Derivatives. Experimental and Theoretical Studies. Chem. Mater. 2001, 13, 2528-2536.

45. Grigalevicius, S. 3,6(2,7),9-Substituted carbazoles as Electroactive Amorphous Materials for Optoelectronics. Synth. Met. 2006, 156, 1-12.

46. Wong, K.-T.; Liao, Y.-L.; Lin, Y.-T.; Su, H.-C.; Wu, C.-c. Nonconjugated Hybrid of Carbazole and Fluorene: A Novel Host Material for Highly Efficient Green and Red Phosphorescent OLEDs. Org. Lett. 2005, 7, 5131-5364.

47. Wu, F.-I.; Shih, P.-I; Yuan, M.-C.; Dixit, A.K.; Shu, C.-F.; Chung, Z.-M.; Diau, E.W.-G. Novel Distyrylcarbazole Derivatives as Hole-transporting Blue Emitters for Electroluminescent Devices. J. Mater. Chem. 2005, 15, 4753-4760.

48. Cha, S.W.; Joo, S.-H.; Jeong, M.-Y.; Jin, J.-I. Balancing Charge Carrier Mobility by Constructing Chemical Structures to Contain both Hole- and Electron-transporting Moieties in Electroluminescent Organic Compounds. Synth. Met. 2005, 150, 309-316.

49. Kremser, G.; Hofmann, O.T.; Sax, S.; Kappaun, S.; List, E.J.W.; Zojer, E.; Slugovc, C. Synthesis and Photophysical Properties of 3,6-Diphenyl-9-hexyl-9H-carbazole Derivatives Bearing Electron Withdrawing Groups. Monatsh. Chem. 2008, 139, 223-231. 
50. Niedermair, F.; Waich, K.; Kappaun, S.; Mayr, T.; Trimmel, G.; Mereiter, K.; Slugovc, C. Heteroleptic $\kappa^{2}\left(\mathrm{~N}, \mathrm{C}^{2}\right)$-2-phenylpyridine Platinum Complexes: The Use of bis(pyrazolyl)borates as Ancillary Ligands. Inorg. Chim. Acta 2007, 360, 2767-2777.

51. Niedermair, F.; Kwon, O.; Zojer, K.; Kappaun, S.; Trimmel, G.; Mereiter, K.; Slugovc, C. Heteroleptic Platinum(II) Complexes of 8-Quinolinolates Bearing Electron Withdrawing Groups in 5 Position. Dalton Trans. 2008, 4006-4014.

52. Dixon, I.M.; Collin, J.P.; Sauvage, J.P.; Flamigni, L.; Encinas, S.; Barigelletti, F. A Family of Luminescent Coordination Compounds: Iridium(III) Polyimine Complexes. Chem. Soc. Rev. 2000, 29, 385-391.

53. Lowry, M.S.; Bernhard, S. Synthetically Tailored Excited States: Phosphorescent, Cyclometalated Iridium(III) Complexes and Their Applications. Chem. Eur. J. 2006, 12, 7970-7977.

54. Goushi, K.; Kwong, R.; Brown, J.J.; Sasabe, H.; Adachi, C. Triplet Exciton Confinement and Unconfinement by Adjacent Hole-transport Layers. J. Appl. Phys. 2004, 95, 7798-7802.

55. Holder, E.; Langeveld, B.M.W.; Schubert, U.S. New Trends in the Use of Transition MetalLigand Complexes for Applications in Electroluminescent Devices. Adv. Mater. 2005, 17, 11091121.

56. Slinker, J.D.; Gorodetsky, A.A.; Lowry, M.S.; Wang, J.; Parker, S.; Rohl, R.; Bernhard, S.; Malliaras, G.G. Efficient Yellow Electroluminescence from a Single Layer of a Cyclometalated Iridium Complex. J. Am. Chem. Soc. 2004, 126, 2763-2767.

57. Nonoyama, M. Benzo[h]quinolin-10-yl-N Iridium(III) Complexes Bull. Chem. Soc. Jpn. 1974, 47, 767-768.

58. Ionkin, A.S.; Marshall, W.J.; Fish, B.M. Synthesis and Structural Characterization of a Series of Novel Polyaromatic Ligands Containing Pyrene and Related Biscyclometalated Iridium(III) Complexes. Organometallics 2006, 25, 1461-1471.

59. King, K.A.; Spellane, P.J.; Watts, R.J. Excited-state Properties of a Triply Ortho-metalated Iridium(III) Complex. J. Am. Chem. Soc. 1985, 107, 1431-1432.

60. Ionkin, A.S.; Marshall, W.J.; Roe, D.C.; Wang, Y. Synthesis, Structural Characterization and the First Electroluminescent Properties of Tris- and Bis-cycloiridiated Complexes of Sterically Hindered Electron-poor 2-(3,5-bis(trifluoromethyl)phenyl)-4-trifluoromethylpyridine. Dalton Trans. 2006, 2468-2478.

61. Tamayo, A.B.; Alleyne, B.D.; Djurovich, P.I.; Lamansky, S.; Tsyba, I.; Ho, N.N.; Bau, R.; Thompson, M.E. Synthesis and Characterization of Facial and Meridional Tris-cyclometalated Iridium(III) Complexes. J. Am. Chem. Soc. 2003, 125, 7377-7387.

62. Huo, S.; Deaton, J.C.; Rajeswaran, M.; Lenhart, W.C. Highly Efficient, Selective, and General Method for the Preparation of Meridional Homo- and Heteroleptic Tris-cyclometalated Iridium Complexes. Inorg. Chem. 2006, 45, 3155-3157.

63. Dedeian, K.; Shi, J.; Shepard, N.; Forsythe, E.; Morton, D. C. Photophysical and Electrochemical Properties of Heteroleptic Tris-Cyclometalated Iridium(III) Complexes. Inorg. Chem. 2005, 44, 4445-4447.

64. Kappaun, S.; Rentenberger, S.; Pogantsch, A.; Zojer, E.; Mereiter, K.; Trimmel, G.; Saf, R.; Möller, K.C.; Stelzer, F.; Slugovc, C. Organoboron Quinolinolates with Extended Conjugated 
Chromophores: Synthesis, Structure, and Electronic and Electroluminescent Properties. Chem. Mater. 2006, 18, 3539-3547.

65. You, Y.; Park, S.Y. Inter-Ligand Energy Transfer and Related Emission Change in the Cyclometalated Heteroleptic Iridium Complex: Facile and Efficient Color Tuning over the Whole Visible Range by the Ancillary Ligand Structure. J. Am. Chem. Soc. 2005, 127, 12438-12439.

66. Kappaun, S.; Sax, S.; Eder, S.; Möller, K.C.; Waich, K.; Niedermair, F.; Saf, R.; Mereiter, K.; Jacob, J.; Müllen, K.; List, E.J.W.; Slugovc, C. 8-Quinolinolates as Ligands for Luminescent Cyclometalated Iridium Complexes. Chem. Mater. 2007, 19, 1209-1211.

67. Kappaun, S.; Eder, S.; Sax, S.; Mereiter, K.; List, E.J.W.; Slugove, C. Organoiridium Quinolinolate Complexes: Synthesis, Structures, Thermal Stabilities and Photophysical Properties. Eur. J. Inorg. Chem. 2007, 4207-4215.

68. Lamansky, S.; Djurovic, P.; Murphy, D.; Abdel-Razzaq, F.; Kwong, R.; Tsyba, I.; Bortz, M.; Mui, B.; Bau, R.; Thompson, M.E. Synthesis and Characterization of Phosphorescent Cyclometalated Iridium Complexes. Inorg. Chem. 2001, 40, 1704-1711.

69. Lamansky, S.; Djurovich, P.; Murphy, D.; Abdel-Razzaq, F.; Lee, H.-E.; Adachi, C.; Burrows, P.E.; Forrest, S.R.; Thompson, M.E. Highly Phosphorescent Bis-Cyclometalated Iridium Complexes: Synthesis, Photophysical Characterization, and Use in Organic Light Emitting Diodes. J. Am. Chem. Soc. 2001, 123, 4304-4312.

70. Hsu, N.-M.; Li, W.-R. Accelerated Discovery of Red-Phosphorescent Emitters through Combinatorial Organometallic Synthesis and Screening. Angew. Chem. 2006, 118, 4244-4248.

71. Yang, C.-H.; Li, S.-W.; Chi, Y.; Cheng, Y.-M.; Yeh, Y.-S.; Chou, P.-T.; Lee, G.-H.; Wang, C.-H.; Shu, C.-F. Heteroleptic Cyclometalated Iridium(III) Complexes Displaying Blue Phosphorescence in Solution and Solid State at Room Temperature. Inorg. Chem. 2005, 44, 77707780 .

72. Sajoto, T.; Djurovich, P.I.; Tamayo, A.; Yousufuddin, M.; Bau, R.; Thompson, M.E. Blue and Near-UV Phosphorescence from Iridium Complexes with Cyclometalated Pyrazolyl or NHeterocyclic Carbene Ligands. Inorg. Chem. 2005, 44, 7992-8003.

73. Mak, C.S.K.; Hayer, A.; Pascu, S.I.; Watkins, S.E.; Holmes, A.B.; Köhler, A.; Friend, R.H. Blueto-green Electrophosphorescence of Iridium-based Cyclometalated Materials. Chem. Commun. 2005, 4708-4710.

74. Jang, H.; Shin, C.H.; Kim, N.G.; Hwang, K.Y.; Do, Y. New Phosphorescent ppy-based Iridium Complexes Containing Electron-withdrawing Groups. Synth. Met. 2005, 154, 157-160.

75. Ragni, R.; Plummer, E.A.; Brunner, K.; Hofstraat, J.W.; Babudri, F.; Farinola, G.M.; Naso, F.; De Cola, L. Blue Emitting Iridium Complexes: Synthesis, Photophysics and Phosphorescent Devices. J. Mater. Chem. 2006, 16, 1161-1170.

76. Chin, C.S.; Eum, M.-S.; Kim, S.y.; Kim, C.; Kang, S.K. Blue-Light-Emitting Complexes: Cationic (2-Phenylpyridinato)iridium(III) Complexes with Strong-Field Ancillary Ligands. Eur. J. Inorg. Chem. 2007, 372-375.

77. Lo, S.-C.; Shipley, C.P.; Bera, R.N.; Harding, R.E.; Cowley, A.R.; Burn, P.L.; Samuel, I.D.W. Blue Phosphorescence from Iridium(III) Complexes at Room Temperature. Chem. Mater. 2006, $18,5119-5129$. 
78. Chou, P.-T.; Chi, Y. Phosphorescent Dyes for Organic Light-Emitting Diodes. Chem. Eur. J. 2007, 13, 380-395.

79. Li, J.; Djurovich, P.I.; Alleyne, B.D.; Yousufuddin, M.; Ho, N.N.; Thomas, J.C.; Peters, J.C.; Bau, R.; Thompson, M.E. Synthetic Control of Excited-State Properties in Cyclometalated Ir(III) Complexes Using Ancillary Ligands. Inorg. Chem. 2005, 44, 1713-1727.

80. Liu, T.; Xia, B.-H.; Zhou, X.; Zhang, H.-X.; Pan, Q.-J.; Gao, J.-S. Theoretical Studies on Structures and Spectroscopic Properties of Bis-Cyclometalated Iridium Complexes. Organometallics 2007, 26, 143-149.

81. Kwon, T.-H.; Cho, H.S.; Kim, M.K.; Kim, J.-W.; Kim, J.-J.; Lee, K.H.; Park, S.J.; Shin, I.-S.; Kim, H.; Shin, D.M.; Chung, Y.K.; Hong, J.-I. Color Tuning of Cyclometalated Iridium Complexes through Modification of Phenylpyrazole Derivatives and Ancillary Ligand Based on ab Initio Calculations. Organometallics 2005, 24, 1578-1585.

82. Bansal, A.K.; Holzer, W.; Penzkofer, A.; Tsuboi, T. Absorption and Emission Spectroscopic Characterization of Platinum-octaethyl-porphyrin (PtOEP). Chem. Phys. 2006, 330, 118-129.

83. Holzer, W.; Penzkofer, A.; Tsuboi, T. Absorption and Emission Spectroscopic Characterization of Ir(ppy)3. Chem. Phys. 2005, 308, 93-102.

84. Koga, Y.; Ueno, K.; Matsubara, K. New Preparative Procedure for Photoluminescent Metallopolymers Having a Biphenyl-2,2'-diyl Iridium(III) Unit Bound to a Phosphine Copolymer Ligand. J. Polym. Sci., Part A: Polym. Chem. 2006, 44, 4204-4213.

85. You, Y.; Kim, S.H.; Jung, H.K.; Park, S.Y. Blue Electrophosphorescence from Iridium Complex Covalently Bonded to the Poly(9-dodecyl-3-vinylcarbazole): Suppressed Phase Segregation and Enhanced Energy Transfer. Macromolecules 2006, 39, 349-356.

86. Jiang, J.; Jiang, C.; Yang, W.; Zhen, H.; Huang, F.; Cao, Y. High-Efficiency Electrophosphorescent Fluorene-alt-carbazole Copolymers N-Grafted with Cyclometalated Ir Complexes. Macromolecules 2005, 38, 4072-4080.

87. Carlise, J.R.; Wang, X.-Y.; Weck, M. Phosphorescent Side-Chain Functionalized Poly(norbornene)s Containing Iridium Complexes. Macromolecules 2005, 38, 9000-9008.

88. Wang, X.-Y.; Prabhu, R.N.; Schmehl, R.H.; Weck, M. Polymer-Based Tris(2phenylpyridine)iridium Complexes. Macromolecules 2006, 39, 3140-3146.

89. Chen, X.; Liao, J.-L.; Liang, Y.; Ahmed, M.O.; Tseng, H.-E.; Chen, S.-A. High-Efficiency RedLight Emission from Polyfluorenes Grafted with Cyclometalated Iridium Complexes and Charge Transport Moiety. J. Am. Chem. Soc. 2003, 125, 636-637.

90. Deng, L.; Furuta, P.T.; Garon, S.; Li, J.; Kavulak, D.; Thompson, M.E.; Frechet, J.M.J. Living Radical Polymerization of Bipolar Transport Materials for Highly Efficient Light Emitting Diodes. Chem. Mater. 2006, 18, 386-395.

91. Wang, X.-Y.; Kimyonok, A.; Weck, M. Functionalization of Polymers with Phosphorescent Iridium Complexes via Click Chemistry. Chem. Commun. 2006, 3933-3925.

92. Kimyonok, A.; Weck, M. Poly(cyclooctene)s with Pendant Fluorescent and Phosphorescent Metal Complexes. Macromol. Rapid Commun. 2007, 28, 152-157.

93. Zhang, K.; Chen, Z.; Yang, C.; Gong, S.; Qin, J.; Cao, Y. Saturated Red-Emitting Electrophosphorescent Polymers with Iridium Coordinating to $\beta$-Diketonate Units in the Main Chain. Macromol. Rapid Commun. 2006, 27, 1926-1931. 
94. Evans, N.R.; Devi, L.S.; Mak, C.S.K.; Watkins, S.E.; Pascu, S.I.; Köhler, A.; Friend, R.H.; Williams, C.K.; Holmes, A.B. Triplet Energy Back Transfer in Conjugated Polymers with Pendant Phosphorescent Iridium Complexes. J. Am. Chem. Soc. 2006, 128, 6647-6656.

95. Kimyonok, A.; Domercq, B.; Haldi, A.; Cho, J.-Y.; Carlise, J.R.; Wang, X.-Y.; Hayden, L.E.; Jones, S.C.; Barlow, S.; Marder, S.R.; Kippelen, B.; Weck, M. Norbornene-Based Copolymers with Iridium Complexes and Bis(carbazolyl)fluorene Groups in Their Side-Chains and Their Use in Light-Emitting Diodes. Chem. Mater. 2007, 19, 5602-5608.

96. Rehmann, N.; Ulbricht, C.; Köhnen, A.; Zacharias, P.; Gather, M.C.; Hertel, D.; Holder, E.; Meerholz, K.; Schubert, U. Advanced Device Architecture for Highly Efficient Organic LightEmitting Diodes with an Orange-Emitting Crosslinkable Iridium(III) Complex. Adv. Mater. 2008, 20, 129-133.

97. Yang, W.; Zhen, H.Y.; Jiang, C.Y.; Su, L.J.; Jiang, J.X.; Shi, H.H.; Cao, Y. Synthesis of Electrophosphorescent Polymers Based on Para-phenylenes with Iridium Complexes. Synth. Met. 2005, 153, 189-192.

98. Zhen, H.; Jiang, C.; Yang, W.; Jiang, J.; Huang, F.; Cao, Y. Synthesis and Properties of Electrophosphorescent Chelating Polymers with Iridium Complexes in the Conjugated Backbone. Chem. Eur. J. 2005, 11, 5007-5016.

99. Zhen, H.; Luo, C.; Yang, W.; Song, W.; Du, B.; Jiang, J.; Jiang, C.; Zhang, Y.; Cao, Y. Electrophosphorescent Chelating Copolymers Based on Linkage Isomers of NaphthylpyridineIridium Complexes with Fluorene. Macromolecules 2006, 39, 1693-1700.

100. Liu, S.-J.; Zhao, Q.; Chen, R.-F.; Deng, Y.; Fan, Q.-L.; Li, F.-Y.; Wang, L.-H.; Huang, C.-H.; Huang, W. $\pi$-Conjugated Chelating Polymers with Charged Iridium Complexes in the Backbones: Synthesis, Characterization, Energy Transfer, and Electrochemical Properties. Chem. Eur. J. 2006, 12, 4351-4361.

101. Zhuang, W.; Zhang, Y.; Hou, Q.; Wang, L.; Cao, Y. High-Efficiency, Electrophosphorescent Polymers with Porphyrin-Platinum Complexes in the Conjugated Backbone: Synthesis and Device Performance. J. Polym. Sci., Part A: Polym. Chem. 2006, 44, 4174-4186.

102. Kappaun, S.; Eder, S.; Sax, S.; Saf, R.; Mereiter, K.; List, E.J.W.; Slugovc, C. WPLEDs Prepared from Main-chain Fluorene-iridium(III) Polymers. J. Mater. Chem. 2006, 16, 4389-4392.

(C) 2008 by the authors; licensee Molecular Diversity Preservation International, Basel, Switzerland. This article is an open-access article distributed under the terms and conditions of the Creative Commons Attribution license (http://creativecommons.org/licenses/by/3.0/). 